\title{
Research on Performance Evaluation Indicator System for Presales Manager of Software Development
}

\author{
Yongchang Ren ${ }^{1, a}$, Gaode Qin ${ }^{2, b}$, Houhua Shen ${ }^{3, c}$ \\ ${ }^{1}$ College of Information Science and Technology, Bohai University, Jinzhou, 121013, China \\ ${ }^{2}$ School of Computer Engineering, Shenzhen Polytechnic, Shenzhen, 518055, China \\ ${ }^{3}$ College of Engineering, Bohai University, Jinzhou, 121013, China \\ arycryc@sina.com, ${ }^{b}$ qingaode@szpt.edu.cn, cshenhouhuashh@126.com
}

Keywords: software development, presales manager, performance evaluation, balanced Score card, key performance index

\begin{abstract}
Establishment of the performance appraisal Index system of software project pre-sales manager is are important in human resources management work of the software enterprises, software project can sign the contract, depend on the software project manager's job performance. Performance appraisal for the current problems, use of balance scorecard and critical success factors method, Focus on performance appraisal index system and method to study the process. First analyzes the idea of setting up performance goals, then clear the strategic goals into the organization method of measure, finally, use software project pre-sales manager processes and control points with performance appraisal index system, establish the key performance appraisal index. The result show that performance appraisal is a complex system engineering, balanced score card method and the combination of key success factors is the establishment of pre-sales manager, software project performance appraisal index system of effective methods and effective performance appraisal contribute to corporate strategic objectives achieve.
\end{abstract}

\section{Introduction}

Software project is a pre-creative, innovative work, whether the contract entered into software project largely depends on the software, intellectual input and pre-sales staff performance, and in all pre-sales personnel play a decisive role in the Pre-sales manager for a software project. Pre-sales manager is technical guidance and work of the organizers, he's job performance related to the survival of enterprises, software companies to strengthen the most effective pre-sales manager, is the most direct means of performance appraisal, performance appraisal carried out Premise is to establish reasonable performance appraisal index system. Unlike other software pre-industrial engineering, it's a complex process of change, pre-sales manager of the establishment of performance Appraisal index system can't copy the methods of traditional industrial enterprises. Therefore, establishment of the performance appraisal index system of software project pre-sales manager is a very important work in human resources management software.

\section{Establishment Method of Performance Evaluation Indicator System}

Performance appraisal is according to certain criteria, using scientific methods, the moral of employees, work performance, ability and attitude of a comprehensive inspection and appraisal to determine their job performance and potential management methods. Human resources management is the core of performance management, performance management is the most important part of performance appraisal, and performance appraisal Index through assessment to be embodied [2]. Performance index is to character, job performance, abilities and attitudes, combined with a scientific manner and organizational characteristics, classification projects and standards for the performance appraisal and performance improvement.

Balanced Score Card Method.

Balanced score card (BSC, Balanced Score Card),by Robert Kaplan and David Norton proposed 
a measure of the performance of strategic management tool in 1992.Using the words of the founder:"BSC is a performance management tool that corporate strategic objectives, break down into a specific layer, the mutual balance of performance appraisal index system, and to achieve the periodic assessment of these Index, So as to achieve the objective of corporate strategy to establish a reliable basis for implementation. Since then, BSC has gradually improved from an increase in performance management tool to a strategic height, the central importance of evolving into a strategic management system. The method from the financial, customer, internal business process, learning and growth latitude to assess and improve business performance, encourage enterprises to achieve strategic goals and consciously build system [3].

These four latitudes constitute the basic framework of the BSC, as shown in Fig. 1.

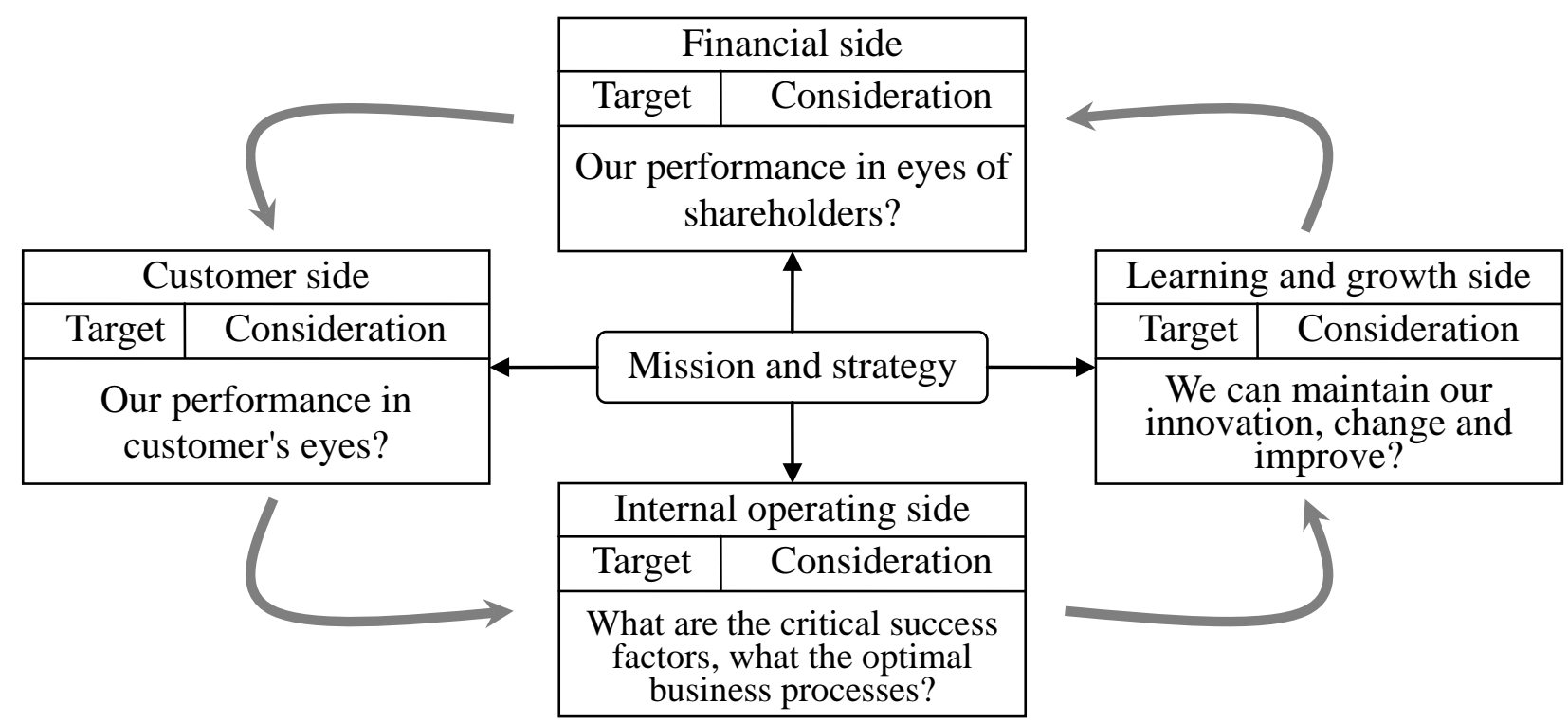

Fig. 1 The basic framework of the balanced score card

In today's information age, the only financial Index used to measure business performance can not meet the needs of enterprise development. BSC measure of business from various angles future performance, make up for the lack of financial metrics, for the short-term goals and long-term business objectives, measure performance and financial performance of non-financial measures, between lagging Index and indexes advanced, internal growth Outside the enterprise to meet customer needs with the balance between the state, is a comprehensive measure of management performance corporate strategy, strategic control of the important tools and methods.

BSC as a strategic performance management and evaluation tools, stress that financial, customer, internal business and learning and growth perspective to measure the business [4]. Financial Index is the ultimate business goal, but also the fundamental basis for existence of the business; enhance corporate profitability, must be customer-focused, to meet customer needs, improve customer satisfaction; which in turn requires the enterprises to strengthen their own capacity, improve operational processes in the, Customer relations, innovation process and regulatory and environmental efficiency of the four aspects of the operation; and improve internal efficiency on the premise that employees must be able to continuously learn and grow.

\section{Critical Success Factor Method.}

Critical success factors method is based on the corporate vision, strategy and core values, the process of business operations in a number of key success factors were extracted and summarized in order to build business-critical performance evaluation index system and performance management systems processes and methods, focusing on the extraction Key Performance Indicator (KPI).

(1) The Concept of Key Performance Indicator

KPI, is a critical success factor in the operation of the extraction and induction to companies and organizations, is an objective measure of performance Index of the quantitative management style. KPI comes from the decomposition of the overall strategic objectives enterprise; reflect the most effective way which affect key drivers of value creation [5]. 
The establishment of KPI's meaning: manager will focus on driving business performance has the largest action, timely diagnosis of problems in production and business activities, take action to improve the level of performance improvement measures. Decomposition of KPI Index do want to ensure that employees the most important core work.KPI for performance-based management, organizations can ensure that truly contribute to behavior to be encouraged. Reached by KPI commitments, employees and managers can expect in the work, performance and future development areas such as communications, so to communicate KPI is the cornerstone of the performance.

KPI law is consistent with an important management principle-"twenty-eight principle". The enterprise value creation process, there is a "20/80"rule, $20 \%$ of the key personnel to create $80 \%$ of the value. In each department and each employee who "twenty-eight principle" applies, $80 \%$ of the tasks of key actors from $20 \%$ complete. Seize $20 \%$ of the key actors, analysis and measurement, performance evaluation will be able to grasp the center of gravity.

The point is the establishment of KPI process, plan and systematic, aim at establishing a mechanism within the enterprise strategy into the process and activities, so as to continuously enhance their core competitiveness and achieve sustained development.KPI can be implemented through the company's goals and business focus, tend to pass the value of the company, effectively motivate employees, increase in per capita benefits and promote the company and employee performance improvement and upgrading.

(2) Three Levels of Key Performance Indicator

Performance can be divided into organizational performance, team performance, individual performance three levels. When evaluating the performance of organizations use enterprise-level KPI, when evaluating the performance of departments use departmental KPI, and the use of individual performance evaluation of individual KPI.KPI includes the three levels, namely enterprise KPI,KPI and specific positions departmental KPI (or individual KPI). The implementation of performance management, they aren't entirely independent because business performance relies on personal performance and individual performance is the ultimate goal of improving business performance. Therefore, individual performance appraisal, they need individual assessment KPI, but also appropriate where the sector assessment KPI, this can be personal interests and departmental interests, the interests of effective organization together.KPI development in specific, the first use of brainstorming and fishbone analysis to identify business focus, that focus on business valuation, and identify key areas of key business performance Index, namely enterprise KPI; and then break into the enterprise KPI Departments to form a departmental KPI, to determine the evaluation index system; be decomposed to the corresponding departments KPI, with individual positions to form individual KPI. It can be said of the department and individual KPI system that established and evaluate process itself is the unity of the various departments work towards the process of corporate strategic objectives.

\section{Establishment of Performance Evaluation Indicator System}

General process for the implementation of the balanced score card: a clear corporate vision and strategy goals, the organization's business strategy into a series of measurable Index, strategy and corporate, departmental and individual short-term goals linked to specific implementation strategy, feedback and medium-term adjustment, amendment to establish a sound management system.

The Idea of the Establishment of Performance Objectives.

Performance objectives established by assessing the company's managers and people to work, performance measures should be responsible and to discuss the process of consultation and consensus. Emphasis on employee participation in goal setting to discuss the process to determine the importance of their objectives, only authorized staff can effectively motivate staff objectives. The establishment of performance objectives as shown in Fig. 2 [6].

Specific performance goals established in accordance with ideas as follows:

$>$ Organizational strategy based on decomposition of the main objectives of this department. 
$>$ Based on the objectives of the sector, a clear mission of personal job responsibilities that individuals assume the tasks.

$>$ According to individual work plan tasks,

$>$ SMART principles in accordance with work plans to extract from the personal key performance Index (divided into quantitative Index and qualitative Index).

\begin{tabular}{|c|}
\hline Business situation \\
\hline Business forecasting \\
\hline Job description \\
\hline
\end{tabular}

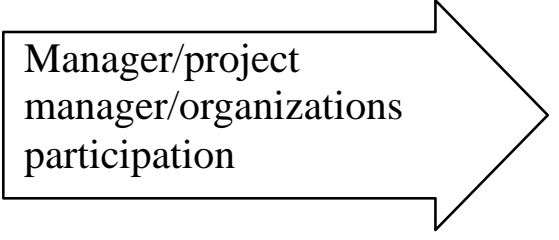
Corporate objectives and KPI
Department objectives and KPI
Personal goals and KPI

Fig.2 Performance goal setting ideas

\section{Organizational Strategic Goals into Measure Index.}

Balanced Scorecard method to organizational strategy and a set of measurable Index linked to corporate strategy be implemented effectively [7]. Gradually to organizational strategy into financial, customer, internal business processes, learning and growth measure four aspects.

Four aspects of the Balanced Scorecard are not independent of each other, but a causal chain, showing the performance and the relationship between performance motivations. Improved operating results for the product or service must be made to win the trust of customers; make the trust of customers, to provide customers with products, for improving internal production process; improve internal production process, workers must be trained to develop new Information System.

Summarized in four aspects of the Balanced Scorecard, usually software company specific strategic objectives such as shown in Table 1.

Table 1. Software Company Strategic Objectives

\begin{tabular}{c|l}
\hline Target name & Target content \\
\hline Finance & $\begin{array}{l}\text { Focused on efficiency goals, strive to maximize our enterprise value, enhance the } \\
\text { market competitiveness }\end{array}$ \\
\hline $\begin{array}{c}\text { Internal } \\
\text { processes }\end{array}$ & $\begin{array}{l}\text { As the development of the management and protection of internal control, } \\
\text { continuously improve operational management and risk prevention }\end{array}$ \\
\hline $\begin{array}{c}\text { Customer } \\
\text { Satisfaction }\end{array}$ & $\begin{array}{l}\text { Customer center, constantly improve service levels, complete of projects timely, } \\
\text { strengthen the quality of projects }\end{array}$ \\
\hline $\begin{array}{c}\text { Learning and } \\
\text { growth }\end{array}$ & $\begin{array}{l}\text { Comprehensively improve the quality of cadres and staff, vigorously promote the } \\
\text { progress of the project and the technical and management innovation }\end{array}$ \\
\hline
\end{tabular}

\section{Key Performance Index.}

Project Manager Software pre-sales positions as a business management class, the process critical control points include time, cost, risk, and results of four aspects. Critical control points for each process analysis, the initial establishment of performance index shown in Table 2.

Table 2. Software Project of Pre-sales Manager and Control Points with Which the Performance Index System

\begin{tabular}{c|c|c|c|c}
\hline Category & Time & Cost & Risk & Result \\
\hline $\begin{array}{c}\text { pre-sales } \\
\text { project } \\
\text { manager }\end{array}$ & $\begin{array}{c}\text { Rate of pre-work } \\
\text { completed on time }\end{array}$ & $\begin{array}{c}\text { Labor and other } \\
\text { costs of budget } \\
\text { achievement rate }\end{array}$ & $\begin{array}{c}\text { The } \\
\text { possibility } \\
\text { of extension }\end{array}$ & $\begin{array}{c}\text { Pre-sales are } \\
\text { completed as planned, } \\
\text { the project bid }\end{array}$ \\
\hline
\end{tabular}

Test of performance index, which do not conform should be modified or eliminated. Specific principles are: comprehensible, controllable, can be implemented, trusted, measurable, low-cost access, consistent with the overall strategic goals, consistent with the overall performance indicator system.

After finishing the test and obtained the software to meet the requirements of key performance index of the project pre-sales manager, according to the principles of the Balanced Scorecard to establish four categories of index, key performance index to form a sort, the formation of KPI system [8]. Pre-finished software project manager, key performance index shown in Table 3. 
Table 3. Software Project of Pre-sales Manager Key Performance Index

\begin{tabular}{c|l}
\hline Dimensional & key performance index \\
\hline \multirow{5}{*}{ Finance } & $\begin{array}{l}\text { Excellent work and for pre-sale more than originally planned amount of } \\
\text { the contract } \\
\text { Save cost= Number of days in advance to complete the pre-project*the } \\
\text { cost of pre-project work }\end{array}$ \\
\hline \multirow{5}{*}{ Customer } & $\begin{array}{l}\text { File management quality } \\
\text { Work plan and work records } \\
\text { On collaboration with other sectors } \\
\text { Handling of major issues } \\
\text { Completion time of each phase of the project pre-conditions }\end{array}$ \\
& $\begin{array}{l}\text { New demands of customers } \\
\text { On the level of customer care and communication } \\
\text { Reaction and response capabilities } \\
\text { Implementation of the commitments } \\
\text { Service quality, quality } \\
\text { Service efficiency } \\
\text { Pre-project completion time } \\
\text { Level of comprehensive coordination }\end{array}$ \\
\hline Learning and & $\begin{array}{l}\text { Pre-project manager job satisfaction } \\
\text { growth } \\
\text { Stable rate of pre-project manager }\end{array}$ \\
\hline
\end{tabular}

\section{Conclusion}

Performance management as a more complex system engineering, in the implementation process faces many links are carefully considered, prudent operation, or implementation of performance management is not only difficult to achieve organizational goals play a positive role, but will play a negative obstacles effect. Therefore, enterprises in the implementation of performance management, they need to pay attention to the overall planning process, but also focus on improving the management philosophy, management, optimization methods, the use of appropriate management tools of the corporate culture of performance management, so that the implementation of performance management can help companies Strategic objectives.

\section{References}

[1] B. H. He, "Research of Standardization of performance management processes," www.boraid.com, 2009-08-05.

[2] Y. Y. Huang. "Research of Telecommunications project management of pre-sales phase of the project," Master's degree of Beijing University of Posts and Telecommunications, 2008.

[3] Q. Ren, "Research of X pre-sales technical staff performance management company," Master's degree of Nanjing University of Science and Technology, 2008.

[4] 51CTO Technology Forum. "The contents of the various stages of pre-work and notes," bbs.51cto.com, 2009-06-10.

[5] rs of Small and Medium Enterprise Performance Management Software," Master's degree of Beijing University of Posts and Telecommunications, 2006.

[6] W. Wu, "Research of Members of Small and Medium Enterprise Performance Management Software," Enterprise economy, vol. 30, no. 9, pp. 113-114, 2009.

[7] B. Xu, "Research of Performance Management Software Project Manager," Master's degree of Beijing Jiaotong University, 2006.

[8] J. M. Zhao, "Research of Pre-sales project management software system integration of information security," Journal of Hunan First Normal University, vol. 8, no. 3, pp. 96-98, 2008. 